\title{
Differences in Parenting Stress, Parenting Attitudes, and Parents' Mental Health According to Parental Adult Attachment Style
}

\author{
Do Hoon Kim', Na Ri Kang ${ }^{1}$, and Young Sook Kwack ${ }^{2}$ \\ 1 Department of Psychiatry, Jeju National University Hospital, Jeju, Korea \\ ${ }^{2}$ Department of Psychiatry, Jeju National University School of Medicine, Jeju, Korea
}

\begin{abstract}
Objectives: We aimed to compare the differences in parenting stress, parenting attitudes, and parents' mental health between different adult attachment styles.

Methods: Forty-four parents who completed a parental education program were enrolled in our study. They completed the Korean version of the Experience of Close Relationship Revised, Korean-Parenting Stress Index-Short Form, Maternal Behavior Research Instrument, and Symptom Checklist-90-Revised.

Results: The avoidant attachment score positively correlated with parenting stress. The anxious attachment score showed a positive relationship with parenting stress, hostile parenting attitude, and psychopathology, but a negative association with an affectionate parenting attitude. The secure attachment group exhibited a more autonomous, affectionate parenting style and a less hostile parenting attitude and less parenting stress than the insecure attachment group. Dismissing-avoidant attachment parents reported significantly higher parenting stress scores than secure attachment parents. Preoccupied and fearful-avoidant attachment parents displayed a more hostile parenting style than secure attachment parents. Dismissing-avoidant and preoccupied parents reported a less affectionate parenting attitude than secure attachment parents.

Conclusion: There were differences in parenting stress, parenting attitudes, and parents' mental health depending on the adult attachment style. More specific education and interventions based on parental attachment type are necessary for parents.
\end{abstract}

Key Words: Adult attachment; Parenting stress; Parenting style; Mental health.

Received: April 24, 2018 / Revision: September 3, 2018 / Accepted: October 2, 2018

Address for correspondence: Young Sook Kwack, Department of Psychiatry, Jeju National University School of Medical, 15 Aran $13-$ gil, Jeju 63241, Korea Tel: +82-64-717-1850, Fax: +82-64-717-1849, E-mail: yskcpy@jejunu.ac.kr

\section{INTRODUCTION}

Attachment in the early stages of life can be consistently identified in subsequent developmental stages, and affects individual feelings, thoughts, and expectations of interpersonal relationships over a lifetime [1]. Adult attachment theory implies that attachment in early childhood continues throughout adulthood and is applied to intimate interpersonal relationships, including parent-child relationships [2].

According to Bartholomew [3], insecure attachment in adulthood can be divided into three groups: preoccupied, dismissive-avoidant, and fearful-avoidant. People with preoccupied attachment display a negative view-of-self and a positive view-of-others. The attachment system is hyperactivated in the face of emotional distress or threats and hypervigilant

This is an Open Access article distributed under the terms of the Creative Commons Attribution Non-Commercial License (https://creativecommons.org/licenses/by-nc/4.0) which permits unrestricted non-commercial use, distribution, and reproduction in any medium, provided the original work is properly cited. to the possibility of rejection or abandonment [4]. People with fearful-avoidant attachment avoid close involvement with others to protect themselves from anticipated rejection by others. People with dismissing-avoidant attachment have a positive view-of-self but a negative view-of-others. They have high self-confidence, want to control relationships, and tend to deny their personal distress [5].

Parenting stress is an important variable affecting parental care. Parenting stress is defined as the subjective feelings of parents when they have a repeated negative experience while parenting their children. It has a decisive impact on parenting behavior and the quality of the parent-child interaction [6]. Previous studies have suggested the presence of significant associations between a parent's attachment style and parenting stress. Most of these studies found that insecure attachment styles were related to greater parenting stress $[7,8]$.

Parenting style refers to the attitudes, interaction, thoughts, and behaviors observed in the parenting process in general. 
The parenting style creates an emotional context in which socialization efforts and family interactions occur [9]. It is also significantly associated with the parents' attachment styles. Compared to insecure mothers, secure mothers report stronger feelings of closeness to their child. This security is also associated with greater support-seeking and problemfocused coping [10].

The presentation of psychopathology differs somewhat with an insecure attachment style because of different coping mechanisms. In particular, insecure attachment may create a vulnerability to psychopathology because of inflexible maladaptive strategies for interacting with the world [11]. The development of psychopathology in individuals with preoccupied attachment is related to a high incidence of mood disturbance and anxiety; moreover, dismissing attachment strategies have been linked to externalizing disorders [12].

Previous studies [13-15] have shown that parents' attachment styles have a complex interrelationship with parenting stress, parenting styles, and parents' mental health. There have been many studies conducted on adult attachment, but these studies only researched specific subjects, such as the mothers of infants or preschoolers, and analyzed simple relationships using limited variables [13-15]. Moreover, there is a lack of studies of how specific subtypes of insecure attachment relate to a particular aspect of parenting. In this study, we measured several variables that affect parenting, including parenting stress, parenting attitude, and parents' mental health. The primary goal of this study was to explore parenting style, parenting stress, and parents' psychopathology according to their adult attachment style. In particular, we evaluated how parenting behaviors and parenting stress differ depending on insecure attachment subtypes.

\section{METHODS}

\section{Participants and procedures}

The subjects were recruited from participants who were enrolled in a parent education program. A total of 44 parents in their 20s, 30s, and 40s participated. We measured the subjects' demographic characteristics, parenting stress, parenting style, adult attachment style, and general mental health using a questionnaire administered before the education program. Written informed consent was obtained. The current study procedures were approved by the Institutional Review Board (JEJUNUH 2018-11-002).

\section{Assessment}

\section{Experiences in Close Relationship-Revised (ECR-R)}

The Experiences in Close Relationship-Revised (ECR-R)

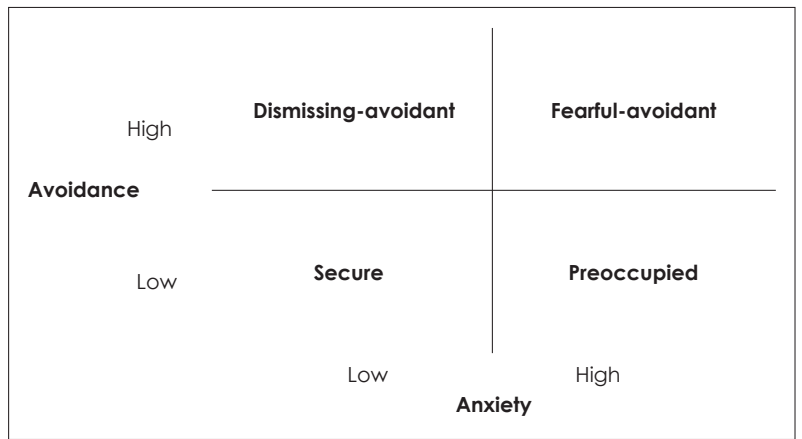

Fig. 1. Model of adult attachment style.

survey is designed to evaluate the responder's attachment style to significant others. The ECR-R contains a total of 36 items divided into two subscales. Each subscale consists of 18 questions and reflects the participant's avoidance attachment and anxious attachment. Each question is scored on a seven-point Likert scale. All participants were asked to complete the Korean version of the ECR-R [16] and the Cronbach's alpha score for this study was 0.65 . Similar to previous studies $[15,17]$. We classified the attachment style as a combination of the attachment-avoidance dimension and attachment-anxiety dimension based on the average score (Fig. 1). Subjects who received scores below the average score in both dimensions were considered to have secure attachment. Participants who were not included in the secure attachment group, were classified into the insecure attachment group. The insecure attachment group was divided into three sub-groups (preoccupied, dismissing-avoidant, and fearful-avoidant) based on the average score. The preoccupied attachment group showed lower than average scores in the attachment-avoidance domain and higher than average scores in the attachment-anxiety domain. The dismissing-avoidant attachment group displayed the opposite pattern to the preoccupied attachment group (i.e., high avoidant score and low anxiety score). The group with higher than average scores in both domains was classified as the fearful-avoidant attachment style group.

\section{Korean-Parenting Stress Index-Short Form (K-PSI-SF)}

The Korean-Parenting Stress Index-Short Form (K-PSI-SF) is a parent-rated scale that measures the level of parenting stress in parents with children aged 1 to 12 years. This scale was developed to identify the characteristics of children and factors that cause their parents stress. It consists of three subscales: Parental Distress, Parent-Child Dysfunctional Interaction, and Difficult Child. This scale comprises 36 questions rated on a five-point Likert scale ranging from one (not present at all) to five (present and marked) and each subscale consists of 13 questions. Higher scores indicate greater experience of parenting stress. The Cronbach's alpha score was 0.82 . 
All participants were asked to complete the K-PSI-SF [18].

\section{Maternal Behavior Research Instrument (MBRI)}

The Maternal Behavior Research Instrument (MBRI) is a self-reported scale composed of 47 items that measures maternal parenting style. Four parenting styles can be investigated with this scale, which include affective (e.g., "It is fun to spend time with my child"), rejecting (e.g., "I ignore my child's demands"), autonomic (e.g., "I let my child do his/her own things alone"), and controlling (e.g., "Children should by all means be obedient to their parents") styles. The affective, autonomic, and controlling parenting style subscales each consist of 12 questions, whereas the rejecting style subscale consists of 11 questions. Each question is rated on a scale of one to five, with subscale scores ranging from 12-60 (rejecting style: 11-55). The sum of the scores for each subscale determines the parenting attitude; the higher the score, the more the mother tends to display that particular style of parenting. In our study, Cronbach's alpha was 0.62. All participants were asked to complete the Korean version of the MBRI [19].

\section{Symptom Checklist-90-Revised (SCL-90-R)}

The Symptom Checklist-90-Revised (SCL-90-R) is a self- rated scale that evaluates general mental health and various psychiatric symptoms [20]. It consists of 90 items rated on a five-point Likert scale range from zero (no problems) to four (very serious). It consists of symptom scales and global indices (Global Severity Index, Positive Symptom Distress Index, and Positive Symptom Total). The symptom scales assess whether the respondents have experienced nine major psychiatric symptoms (somatization, obsession-compulsive, interpersonal sensitivity, depression, anxiety, hostility, phobic anxiety, paranoid ideation, and psychoticism) in the past seven days. Higher scores on the SCL-90-R indicate severe psychological distress. The internal consistency coefficient alpha was 0.96 .

\section{Statistical analyses}

All statistical analyses were performed using SPSS 23.0 for Windows (IBM Corp., Armonk, NY, USA), and the significance level was set at $\mathrm{p}<0.05$. Cronbach's alpha score was calculated for each scale to determine the reliability level. A correlation analysis was conducted to reveal associations between clinical variables. We compared demographic characteristics, parenting style, and parenting stress between the secure and insecure attachment groups. The independent t-test

Table 1. Socio-demographic characteristics of the subjects

\begin{tabular}{|c|c|c|c|c|}
\hline \multirow{2}{*}{ Classification } & \multirow{2}{*}{ Subjects (n, \%) } & \multicolumn{2}{|c|}{ Attachment style (n) } & \multirow{2}{*}{$\chi^{2} / p$} \\
\hline & & Secure & Insecure & \\
\hline \multicolumn{5}{|l|}{ Age (years) } \\
\hline 35 & $13(29.5)$ & 9 & 4 & \multirow[t]{3}{*}{$7.388 / 0.117$} \\
\hline $36-40$ & $15(34.1)$ & 6 & 9 & \\
\hline$\geq 41$ & $16(36.4)$ & 5 & 11 & \\
\hline \multicolumn{5}{|l|}{ Education } \\
\hline High school & $8(18)$ & 2 & 6 & \multirow[t]{3}{*}{$2.687 / 0.261$} \\
\hline University & $35(80)$ & 17 & 18 & \\
\hline No answer & $1(2)$ & 1 & 0 & \\
\hline \multicolumn{5}{|l|}{ Monthly income (million won) } \\
\hline $100-200$ & $9(20)$ & 3 & 6 & \multirow[t]{4}{*}{$1.567 / 0.815$} \\
\hline $200-300$ & $19(43)$ & 8 & 11 & \\
\hline$>300$ & $13(30)$ & 7 & 6 & \\
\hline No answer & $3(7)$ & 2 & 1 & \\
\hline \multicolumn{5}{|c|}{ Consideration of children's psychiatric evaluation } \\
\hline Yes & $25(57)$ & 10 & 15 & \multirow[t]{2}{*}{$0.695 / 0.405$} \\
\hline No & $19(43)$ & 10 & 9 & \\
\hline \multicolumn{5}{|c|}{ Child is currently receiving psychiatric treatment } \\
\hline Yes & $14(32)$ & 5 & 9 & \multirow{2}{*}{$0.786 / 0.375$} \\
\hline No & $30(68)$ & 15 & 15 & \\
\hline \multicolumn{5}{|l|}{ Presence of physical illness or disability } \\
\hline Yes & $9(20)$ & 5 & 4 & \multirow{2}{*}{$0.466 / 0.495$} \\
\hline No & $35(80)$ & 15 & 20 & \\
\hline Number of children (mean \pm SD) & $1.84 \pm 0.77$ & $1.85 \pm 0.87$ & $1.83 \pm 0.70$ & $0.386^{*}$ \\
\hline
\end{tabular}

${ }^{*} \mathrm{p}$-value of t-test. SD: standard deviation 


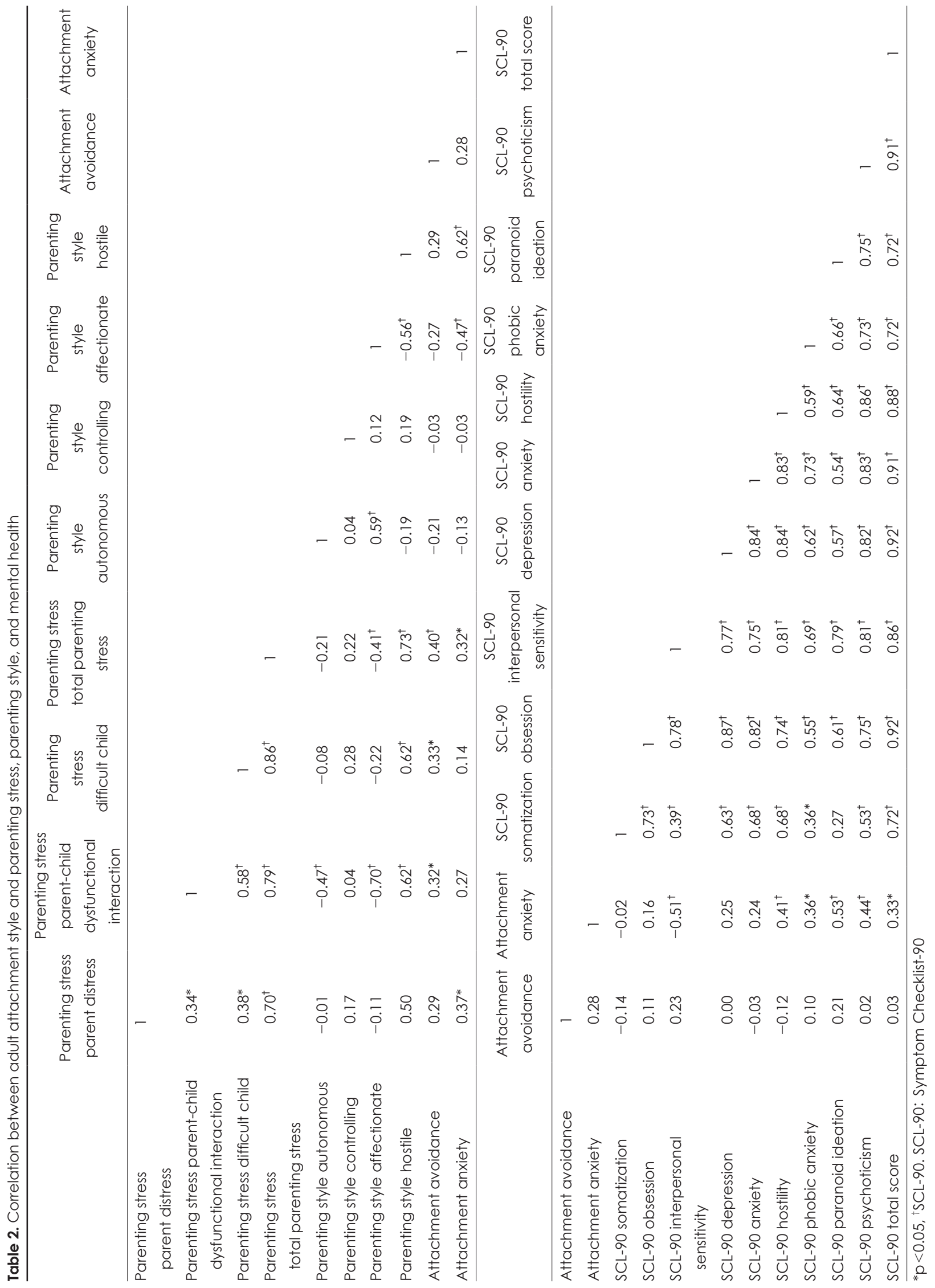


was used for continuous variables and a chi-squared test was performed for categorical variables. We used a one-way analysis of variance (ANOVA) to analyze differences in parenting between secure attachment and the three types of insecure attachment.

\section{RESULTS}

\section{Sociodemographic characteristics of the subjects}

The sociodemographic data of the subjects are described in Table 1. Most of the respondents were in their mid-30s or older, highly educated (university graduates, $80 \%$ ) and reported a monthly family income over 200 million won (73\%). Additionally, $57 \%$ of participants were concerned about their children's psychiatric evaluation. At the time of the study, 32\% of the subjects' children were under psychiatric treatment and $20 \%$ of them had physical illness or disability. The participants had a mean of 1.84 children. There were no significant differences in the sociodemographic data of the subjects according to their attachment style.

\section{Correlation between adult attachment style and parenting stress, style, and mental health}

The association between adult attachment and parenting stress, parenting style, and psychiatric symptoms was analyzed using Pearson's correlation coefficient. As displayed in Table 2, the participant's attachment-avoidance scores were positively associated with the following subscales of the K-PSISF: Parent-Child Dysfunctional Interaction $(\gamma=0.32, \mathrm{p}<0.05)$, Difficult Child $(\gamma=0.33, \mathrm{p}<0.05)$, and total parenting stress $(\gamma=0.40, \mathrm{p}<0.01)$. The participants' attachment-anxiety scores showed a positive association with total parenting stress $(\gamma=$ $0.32, \mathrm{p}<0.05)$, interpersonal sensitivity $(\gamma=-0.51, \mathrm{p}<0.01)$, hostility $(\gamma=0.41, \mathrm{p}<0.01)$, phobic anxiety $(\gamma=0.36, \mathrm{p}<0.05)$, paranoid ideation $(\gamma=0.53, \mathrm{p}<0.05)$, psychoticism $(\gamma=0.44, \mathrm{p}<0.05)$, and hostile parenting style $(\gamma=0.62, \mathrm{p}<0.01)$. Conversely, there was a negative correlation between the affective parenting style and attachment-anxiety score $(\gamma=0.47, \mathrm{p}<0.01)$.

\section{Comparison between the secure attachment and insecure attachment groups}

Table 3 shows the differences between the variables of the secure and insecure attachment groups. Parents in the insecure attachment group suffered from higher total parenting stress $(p=0.007)$ than parents in the secure attachment group. They showed significantly higher scores in the Parent-Child Dysfunctional Interaction ( $\mathrm{p}=0.011)$ and Difficult Child $(\mathrm{p}=$ $0.009)$ subscales than secure attachment parents. They also

Table 3. Comparison between secure attachment group and insecure attachment group

\begin{tabular}{|c|c|c|c|c|}
\hline & Secure $(n=20)$ & Insecure $(n=24)$ & \multirow{2}{*}{$\mathrm{T}$} & \multirow{2}{*}{$\mathrm{p}$} \\
\hline & Mean (SD) & Mean (SD) & & \\
\hline \multicolumn{5}{|l|}{ Parenting stress (K-PSI-SF) } \\
\hline Parent distress & 32.30 (8.79) & $34.91(7.03)$ & -1.09 & 0.279 \\
\hline Parent-child dysfunctional interaction & $23.75(7.03)$ & $29.37(6.64)$ & -2.66 & 0.011 \\
\hline Difficult child & $29.15(10.61)$ & $37.04(8.62)$ & -2.72 & 0.009 \\
\hline Total parenting stress & $85.20(22.69)$ & $101.33(15.07)$ & -2.81 & 0.007 \\
\hline \multicolumn{5}{|l|}{ Psychopathology (SCL-90-R) } \\
\hline Somatization & $47.50(12.13)$ & $43.45(6.42)$ & 1.34 & 0.191 \\
\hline Obsessive-compulsive & $48.40(12.64)$ & $48.33(8.98)$ & 0.02 & 0.984 \\
\hline Interpersonal sensitivity & $45.05(8.30)$ & $50.29(11.98)$ & -1.65 & 0.106 \\
\hline Depression & $47.15(11.19)$ & $48.37(9.96)$ & -0.38 & 0.703 \\
\hline Anxiety & $43.70(9.70)$ & $45.16(8.64)$ & -0.53 & 0.599 \\
\hline Hostility & $49.85(12.76)$ & $52.08(13.72)$ & -0.55 & 0.582 \\
\hline Phobic anxiety & $43.70(4.63)$ & $46.91(10.07)$ & -1.31 & 0.196 \\
\hline Paranoid ideation & $43.10(6.38)$ & 46.87 (9.19) & -1.54 & 0.129 \\
\hline Psychoticism & $44.30(6.68)$ & $46.16(8.67)$ & -0.78 & 0.436 \\
\hline Total score & $44.75(10.81)$ & $46.20(10.01)$ & -0.46 & 0.645 \\
\hline \multicolumn{5}{|l|}{ Parenting type (MBRI) } \\
\hline Autonomous & $41.70(5.68)$ & $38.50(4.77)$ & 2.03 & 0.049 \\
\hline Controlling & $37.65(7.16)$ & $35.62(4.39)$ & 1.15 & 0.257 \\
\hline Affectionate & $48.20(5.31)$ & $41.04(6.18)$ & 4.07 & 0.000 \\
\hline Hostile & $28.60(6.59)$ & $35.62(4.48)$ & -4.18 & 0.000 \\
\hline
\end{tabular}

K-PSI-SF: Korean-Parenting Stress Index-Short Form, MBRI: Maternal Behavior Research Instrument, SCL-90-R: Symptom Checklist90-Revised, SD: standard deviation 
Table 4. Comparison between the four attachment subgroups

\begin{tabular}{|c|c|c|c|c|c|c|c|}
\hline Variable & $\begin{array}{l}\text { Secure }(a) \\
\quad(n=20)\end{array}$ & $\begin{array}{l}\text { Preoccupied (b) } \\
\qquad(n=6)\end{array}$ & $\begin{array}{l}\mathrm{DA}(\mathrm{c}) \\
(\mathrm{n}=6)\end{array}$ & $\begin{array}{l}\mathrm{FA}(\mathrm{d}) \\
(\mathrm{n}=12)\end{array}$ & $\mathrm{F}$ & $\mathrm{p}$ & Post-hoc* \\
\hline \multicolumn{8}{|l|}{ Parenting stress (K-PSI-SF) } \\
\hline Parent distress & $32.30 \pm 8.79$ & $33.16 \pm 5.91$ & $31.33 \pm 4.63$ & $37.58 \pm 7.84$ & 1.40 & 0.25 & \\
\hline $\begin{array}{l}\text { Parent-child dysfunctional } \\
\text { interaction }\end{array}$ & $23.75 \pm 7.34$ & $27.16 \pm 3.31$ & $31.50 \pm 7.52$ & $29.41 \pm 7.51$ & 2.70 & 0.05 & \\
\hline Difficult child & $29.15 \pm 10.61$ & $32.16 \pm 7.46$ & $42.50 \pm 5.46$ & $36.7 \pm 9.34$ & 3.78 & 0.01 & $c>a$ \\
\hline Total parenting stress & $85.20 \pm 22.69$ & $92.50 \pm 2.16$ & $105.33 \pm 13.90$ & $103.75 \pm 18.10$ & 3.22 & 0.03 & \\
\hline \multicolumn{8}{|l|}{ Psychopathology (SCL-90-R) } \\
\hline Somatization & $47.50 \pm 12.13$ & $41.83 \pm 6.11$ & $41.50 \pm 7.23$ & $45.25 \pm 6.21$ & 0.92 & 0.43 & \\
\hline Obsessive-compulsive & $48.40 \pm 12.64$ & $44.83 \pm 5.03$ & $47.00 \pm 8.76$ & $50.75 \pm 10.41$ & 0.43 & 0.73 & \\
\hline Interpersonal sensitivity & $45.05 \pm 8.30$ & $51.00 \pm 8.00$ & $43.66 \pm 8.38$ & $53.25 \pm 14.34$ & 2.10 & 0.11 & \\
\hline Depression & $47.15 \pm 11.19$ & $47.33 \pm 8.59$ & $43.50 \pm 7.23$ & $51.33 \pm 11.28$ & 0.81 & 0.49 & \\
\hline Anxiety & $43.70 \pm 9.70$ & $43.50 \pm 7.44$ & $43.16 \pm 6.30$ & $46.00 \pm 10.48$ & 0.21 & 0.88 & \\
\hline Hostility & $49.85 \pm 12.76$ & $58.16 \pm 13.84$ & $44.83 \pm 5.77$ & $52.66 \pm 15.56$ & 1.15 & 0.33 & \\
\hline Phobic anxiety & $43.70 \pm 4.63$ & $46.16 \pm 10.49$ & $45.00 \pm 8.04$ & $48.25 \pm 11.33$ & 0.79 & 0.50 & \\
\hline Paranoid ideation & $43.10 \pm 6.38$ & $47.83 \pm 9.86$ & $41.16 \pm 5.07$ & $49.25 \pm 9.82$ & 2.30 & 0.09 & \\
\hline Psychoticism & $44.30 \pm 6.68$ & $47.83 \pm 9.53$ & $40.83 \pm 3.18$ & $48.00 \pm 9.52$ & 1.50 & 0.22 & \\
\hline Total score & $44.75 \pm 10.81$ & $46.16 \pm 8.72$ & $41.50 \pm 6.47$ & $48.58 \pm 11.73$ & 0.69 & 0.56 & \\
\hline \multicolumn{8}{|l|}{ Parenting type (MBRI) } \\
\hline Autonomous & $41.70 \pm 5.68$ & $38.50 \pm 4.50$ & $37.16 \pm 3.97$ & $39.16 \pm 5.45$ & 1.51 & 0.22 & \\
\hline Controlling & $37.65 \pm 7.16$ & $35.66 \pm 4.17$ & $37.16 \pm 5.49$ & $34.83 \pm 4.08$ & 0.63 & 0.59 & \\
\hline Affectionate & $48.20 \pm 5.31$ & $38.50 \pm 4.72$ & $39.83 \pm 7.30$ & $42.91 \pm 6.11$ & 6.52 & 0.00 & $c>b, c$ \\
\hline Hostile & $28.60 \pm 6.59$ & $37.50 \pm 3.27$ & $32.83 \pm 4.79$ & $36.08 \pm 4.52$ & 6.65 & 0.00 & $b, d>a$ \\
\hline
\end{tabular}

Values are presented as the mean \pm standard deviation. a: secure attachment group, b: preoccupied attachment group, c: DA attachment group, and d: fear, FA attachment group. *bonferroni test. DA: dismissing-avoidant, FA: fearful-avoidant, K-PSI-SF: Korean-Parenting Stress Index-Short Form, MBRI: Maternal Behavior Research Instrument, SCL-90-R: Symptom Checklist-90-Revised

reported less autonomic $(\mathrm{p}=0.049)$, more hostile $(\mathrm{p}<0.001)$ and less affectionate $(\mathrm{p}<0.001)$ parenting styles than parents with secure attachment. There was no significant difference between groups with regards to the SCL-90 results.

\section{Comparison between the four attachment subgroups}

The differences between the four attachment subgroups are displayed in Table 4 . The ANOVA found significant group differences in the Difficult Child ( $\mathrm{F}=3.78, \mathrm{p}=0.01)$ and Total Parenting Stress $(\mathrm{F}=3.22, \mathrm{p}=0.03)$ subscales of the K-PSI-SF, and in affectionate parenting style $(\mathrm{F}=6.52, \mathrm{p}=0.00)$ and hostile parenting style $(\mathrm{F}=6.65, \mathrm{p}=0.00)$. In the post-hoc analysis, the dismissing-avoidant group showed a significantly higher score than the secure attachment group in the Difficult Child $(\mathrm{p}=0.024)$ subscale. The preoccupied type $(\mathrm{p}=0.014)$ and fearful-avoidant type $(\mathrm{p}=0.007)$ had a more hostile parenting style than the secure attachment type. The preoccupied type $(\mathrm{p}=$ $0.005)$ and dismissing-avoidant type $(\mathrm{p}=0.020)$ also showed a less affectionate parenting style than the secure group. We did not identify any significant group differences in the SCL-90.

\section{DISCUSSION}

In this study, high levels of attachment-anxiety and attachment-avoidance were associated with total parenting stress. These results are consistent with previous studies that suggest that both attachment avoidance and anxiety are related to greater parenting stress $[8,21]$. However, in this study, the pattern of parenting stress differed between in attachmentavoidance and attachment-anxiety. Attachment-anxiety was particularly associated with Total Parenting Stress, whereas attachment-avoidance was related to the Difficult Child and Parent-Child Dysfunctional Interaction subscales. The chronic activation of the anxious attachment system tends to use distress-intensifying emotional regulation resources, which amplifies negative emotions. People with anxious attachment feel like they do not have proper coping strategies [22]. In the context of parenting, anxious attachment parents concentrate not only on the child's distress but also on their own emotional difficulties, which leads to parenting stress [22]. Conversely, the avoidant attachment style is characterized by devaluation of the importance of close relationships and the desire to maintain a safe emotional distance from others. People with avoidant attachment feel uncomfortable when 
others are distressed and need support and help [23]. People with avoidant attachment may have difficulty having a friendly and warm attitude toward their children because that parenting behavior may be threatening to them. Those aspects of the avoidant attachment style are related to dissatisfaction with the parent-child relationship and the parents' subjective difficulty with their children.

The attachment-anxiety score was associated with interpersonal sensitivity, hostility, phobic anxiety, paranoid ideation, and psychoticism. Similar to our findings, attachmentanxiety is known to be related to the emotional dysregulation aspects of psychopathology, which include dysregulation of anxiety, anger, impulsivity, emotional lability, self-harm, and suspiciousness [4,24]. Attachment-anxiety showed a positive association with a hostile parenting style and negative correlation with an affective parenting style. The affectionate-hostile axis of parenting reflects parental emotional responsiveness and acceptance of their children [19]. Anxious attachment parents have difficulty accepting the emotions of their children because they tend to experience chronic fear of rejection and have a high level of anxiety in intimate relationships [4,25]. Selcuk et al. [26] found that maternal anxiety, but not avoidance, was associated with greater observed conflict in mother-child interactions and was negatively correlated with observed maternal sensitivity. These patterns may lead to a hostile and less affectionate parenting attitude. However, the attachment-avoidance score was not related to psychopathologies or parenting style in our study. The avoidant attachment style is known to be associated with the inhibited components of psychopathology, including restricted emotional expression and social avoidance [24]. Studies have consistently shown that attachment-related avoidance is associated with less sensitive and responsive parental behavior [26,27]. Rholes et al. [28] reported that parents with avoidant attachment showed a significantly less supportive attitude toward their children. These discrepancies may be attributed to the statistical limitations of our study's small sample size and that it did not consider child-based factors, such as temperament or behavioral problems, that affect parenting attitudes.

In our study, the insecure attachment group experienced higher parenting stress than the secure attachment group. Our findings are consistent with previous studies $[8,15,21]$. Although the underlying mechanism of anxious and avoidant attachment [22,23] differ, the insecure attachment style makes it difficult for the parents to appropriately respond to their child's physical and emotional needs. This leads to dissatisfaction with the dysfunctional parent-child interaction, eventually resulting in high parenting stress. These aspects also affect parenting attitude. The insecure attachment group showed a more hostile and less affectionate parenting style than the secure attachment group. Insecure attachment has been proposed as a nonspecific risk factor for psychopathology and is very common among people with a variety of mental disorders [11]. However, there was no significant difference in the measured psychopathology between the attachment groups in our study. It is not sufficient to manifest psychopathology with only insecure attachment, complex interactions with other biological, psychological and social factors are also involved [11]. Therefore, further research regarding the causal links between adult attachment insecurity and psychopathology is necessary.

Preoccupied parents showed more a hostile and less affectionate parenting attitude than secure attached parents. Prior research has shown that preoccupied mothers provide inconsistent parenting with confusing instructions and affect [29]. Moreover, preoccupied mothers displayed significantly more angry/intrusive parenting than dismissing mothers during a structured parent-child interaction session, similar to our findings [30]. Furthermore, fearful-avoidant parents also revealed more a hostile parenting attitude than secure attached parents. Because the attachment anxiety score was significantly associated with the hostile parenting style in our study, high attachment-anxiety in preoccupied or fearful parents may play a role in emotional unacceptance and hostile attitude toward their children [22]. This suggests that attachment-anxiety is associated with hostile parenting. Additionally, the dismissing-avoidant group reported the lowest score for the Parent Distress subscale and highest score for the Difficult-Child scale in our study. They also showed a less affectionate parenting style than the secure group. Crowell and Feldman [29] reported that dismissing mothers tend to be less supportive of and helpful to their children and show a cold, task-focused, controlling parenting style. Although, dismissing mothers struggle to control their relationship with their children, they are likely to deny the emotional stress that they experience during the parenting process.

This study has several limitations. The number of samples in the different attachment groups was insufficient to have the proper statistical power to adequately compare the characteristics of each group. Furthermore, we only used self-reported data to measure the study variables, which could have led to inflated correlations. Future studies should investigate these variables using different methods, including objective and subjective tests. Our study evaluated parenting only from the parent's perspective and did not consider the characteristics of the child, which may affect parent-child interactions. We attempted to analyze differences between groups by only focusing on adult attachment. However, the association between parenting stress and psychopathology is influenced 
not only by the adult attachment style, but also the complex interaction of many factors, such as parental social stress, physical condition, etc. Our findings may have a risk of underestimating these diverse influences and overestimating the importance of the parental adult attachment style. Because all participants in this study were mothers, it was not possible to analyze how the father's attachment style affected parenting. There may be a problem of selection bias because all research subjects were selected from people who have completed a parent education program.

Despite these limitations, our study has several strengths. We measured parenting attitude, parenting stress, and parents' mental health to comprehensively compare differences in parenting variables according to adult attachment style. Our results are important not only to demonstrate that parents with insecure adult attachment display more parenting stress and less optimal parenting, but also that parents with different types of insecure adult attachment show different types of stress and maladaptive parenting. Further studies examining the relationships between adult attachment and parenting variables, including parents' mental health, should be repeated using a larger sample size.

\section{CONCLUSION}

The primary goal of our study was to investigate differences in parenting stress, parenting styles, and mental health according to parental adult attachment.

Parents with secure attachment had less parenting stress and a more positive parenting style. Different patterns of parenting style and stress were reported within the insecure attachment group. Our results demonstrate that parents with the insecure attachment type require an intervention that supports parenting stress. It is necessary to develop specfic forms of education and invention for effective parenting of the insecure attachment type parents.

\section{Acknowledgments}

This work was supported by the research grant of Jeju National University in 2017.

\section{Conflicts of Interest}

The authors have no financial conflicts of interest.

\section{REFERENCES}

1) Main M, Kaplan N, Cassidy J. Security in infancy, childhood, and adulthood: a move to the level of representation. In: Bretherton I, Waters E, editors. Monographs of the society for research in child development. Chicago: University Of Chicago Press;1985. p.66-104.

2) Collins NL, Read SJ. Adult attachment, working models, and relationship quality in dating couples. J Pers Soc Psychol 1990;58:644663.

3) Bartholomew K. Avoidance of intimacy: an attachment perspec- tive. J Soc Pers Relatsh 1990;7:147-178.

4) Mikulincer M, Shaver PR. Attachment in adulthood: structure, dynamics, and change. New York: Guilford Press;2007.

5) Andersen PA, Guerrero LK. Principles of communication and emotion in social interaction. In: Andersen PA, Guerrero LK, editors. Handbook of communication and emotion: research, theory, applications, and contexts. Cambridge: Elsevier;1996. p.49-96.

6) Esdaile SA, Greenwood KM. A comparison of mothers' and fathers' experience of parenting stress and attributions for parent child interaction outcomes. Occup Ther Int 2003;10:115-126.

7) Vieira JM, Ávila M, Matos PM. Attachment and parenting: the mediating role of work-family balance in Portuguese parents of preschool children. Fam Relat 2012;61:31-50.

8) Nygren M, Carstensen J, Ludvigsson J, Sepa Frostell A. Adult attachment and parenting stress among parents of toddlers. J Reprod Infant Psychol 2012;30:289-302.

9) Vandeleur CL, Perrez M, Schoebi D. Associations between measures of emotion and familial dynamics in normative families with adolescents. Swiss J Psychol 2007;66:5-16.

10) Berant E, Mikulincer M, Shaver PR. Mothers' attachment style, their mental health, and their children's emotional vulnerabilities: a 7-year study of children with congenital heart disease. J Pers 2008;76:31-66.

11) Mikulincer M, Shaver PR. An attachment perspective on psychopathology. World Psychiatry 2012;11:11-15.

12) Rosenstein DS, Horowitz HA. Adolescent attachment and psychopathology. J Consult Clin Psychol 1996;64:244-253.

13) Doinita NE, Maria ND. Attachment and parenting styles. Procedia Soc Behav Sci 2015;203:199-204.

14) Hwang S, Hwang $Z$. The causal relationships between parenting stress and the parenting attitudes of infant mothers. Korean J of Child Studies 2015;36:163-176.

15) Moon YK, Min HS. The relationship among mothers with adult attachment, anxiety, depression, and parenting stress who are rearing preschoolers. Journal of Korean Home Management Association 2008;26:165-176.

16) Kim SH, Kim CD, Sherry A. Adaptation of the Experiences in Close Relationships-Revised Scale into Korean: confirmatory factor analysis and item response theory approaches. Seoul: Seoul National Univ.;2004.

17) Brennan KA, Clark CL, Shaver PR. Self-report measurement of adult attachment: an integrative overview. In: Simpson JA, Rholes WS, editors. Attachment theory and close relationships. New York: Guilford Press;1998. p.46-76.

18) Lee K, Chung KM, Park J, Kim H. Reliability and validity study for the Korean version of parenting stress index short form (K-PSI-SF). Korean J Woman Psychol 2008;13:363-377.

19) Kim SJ, Kim YH, Kim KS. Mothers' child-rearing attitude. Korean J Child Health Nurs 2003;9:392-398.

20) Derogatis LR, Rickels K, Rock AF. The SCL-90 and the MMPI: a step in the validation of a new self-report scale. Br J Psychiatry 1976;128:280-289.

21) Kwako LE, Noll JG, Putnam FW, Trickett PK. Childhood sexual abuse and attachment: an intergenerational perspective. Clin Child Psychol Psychiatry 2010;15:407-422.

22) Mikulincer M, Shaver PR, Pereg D. Attachment theory and affect regulation: the dynamics, development, and cognitive consequences of attachment-related strategies. Motiv Emot 2003;27:77-102.

23) Gillath O, Shaver PR, Mikulincer M. An attachment-theoretical approach to compassion and altruism. In: Gilbert P, editor. Compassion: conceptualisations, research and use in psychotherapy. London: Routledge;2005. p.121-147.

24) Crawford TN, John Livesley W, Jang KL, Shaver PR, Cohen P, Ganiban J. Insecure attachment and personality disorder: a twin study of adults. Eur J Pers 2007;21:191-208.

25) Bowlby J. A secure base: clinical applications of attachment theory. 
Oxford: Taylor \& Francis;2005.

26) Selcuk E, Günaydin G, Sumer N, Harma M, Salman S, Hazan C, et al. Self-reported romantic attachment style predicts everyday maternal caregiving behavior at home. J Res Pers 2010;44:544-549.

27) Berlin LJ, Whiteside-Mansell L, Roggman LA, Green BL, Robinson J, Spieker S. Testing maternal depression and attachment style as moderators of Early Head Start's effects on parenting. Attach Hum Dev 2011;13:49-67.
28) Rholes WS, Simpson JA, Friedman M. Avoidant attachment and the experience of parenting. Pers Soc Psychol Bull 2006;32:275-285.

29) Crowell JA, Feldman SS. Mothers' internal models of relationships and children's behavioral and developmental status: a study of mother-child interaction. Child Dev 1988;59:1273-1285.

30) Adam EK, Gunnar MR, Tanaka A. Adult attachment, parent emotion, and observed parenting behavior: mediator and moderator models. Child Dev 2004;75:110-122. 